\title{
Organizing Preconception Care for Women Suffering from Chronic Diseases: Patients' View on the Role of General Practitioners: A Qualitative Study.
}

\section{Laura Admiraal}

Erasmus Medical Centre: Erasmus MC

Marit Schonewille

Amsterdam UMC - Locatie AMC: Amsterdam UMC Locatie AMC

Mireina Eugenia

Erasmus Medical Centre: Erasmus MC

Lydia Schonewille

Amsterdam UMC - Locatie AMC: Amsterdam UMC Locatie AMC

Annemarie Mulders

Erasmus Medical Centre: Erasmus MC

Ageeth Rosman ( $\nabla$ a.n.rosman@hr.nl)

Erasmus MC https://orcid.org/0000-0003-3751-2950

\section{Research article}

Keywords: Chronic medical condition, preconception care, pregnancy

Posted Date: March 17th, 2021

DOl: https://doi.org/10.21203/rs.3.rs-321449/v1

License: (c) This work is licensed under a Creative Commons Attribution 4.0 International License.

Read Full License 


\section{Abstract}

Background: Women suffering from chronic diseases should preferably receive specialized individual preconception care (PCC) by an obstetrician before becoming pregnant. For most chronic diseases it is important that the disease is in remission or under control before conception, aiming for optimal pregnancy outcome. Especially, amongst other considerations, medication use should be monitored for toxicity before starting a pregnancy. Specific case findings followed by a referral to an obstetrician for specialized individual PCC by a general practitioner (GP) could be a solution to improve the uptake of PCC. The aim of this study was to explore patients' views on PCC organized by general practitioners (GP) for women suffering from a chronic disease.

Methods: We recruited participants via a public Facebook message. We asked women suffering from a chronic medical condition, aged 18-42 years, living in the Netherlands and planning to become pregnant to contact the researcher by a personal message. Once contacted, women received additional information about the aim of the study. After reading the study information, women were asked for participation and a digital informed consent was sent. Thereafter, an appointment for a semi-structured interview by telephone, the study intervention, was made. The interviews were audio-taped, transcribed verbatim and member checked. The transcripts were coded and analysed on facilitators and barriers for preconception care by GP's, using NVivo 10.

Results: 45 women replied to the public Facebook message. All women were contacted by the researcher. Finally, 23 women consented to participate in a semi-structured interview by telephone. This resulted in a heterogeneous study population. The participants indicated a range of facilitators and barriers for organizing PCC via the GP. The GP was viewed to be trustworthy, to have knowledge about their medical history and to have a coordinating role but limited knowledge about pregnancy. Patients preferred a referral from the GP to an obstetrician to have a face-to-face preconception consultation together with their medical specialist.

Conclusions: According to women suffering from a chronic disease, PCC is ideally given by an obstetrician and medical specialist in a face-to-face consultation whereby the GP has a coordinating role.

Trial registration: not applicable.

\section{Background}

In the past decade, the number of patients suffering from any chronic medical condition rapidly increased (1). It is expected that the prevalence of chronic diseases under the Dutch population will rise to 7 million in 2030, which is about the half of the Dutch population suffering from any chronic medical condition. These expectations are based on a selection of 109 chronic medical conditions identified by an ICPC-1 code (International Classification of Primary care) (2). A chronic medical condition is defined as a disease whereby the chance on a complete remission is not present or not to be expected (1). The prevalence of chronic diseases under women aged 20-44 years, ranged in 2014 from 324 to 416 per 1,000 women (1). 
Chronic diseases are associated with adverse pregnancy outcomes, such as preterm delivery, low birthweight and preeclampsia (3). These pregnancy complications, coinciding with both reduced shortterm and long-term maternal and neonatal health, develop already during the first trimester of pregnancy (4-6). Moreover, often they already originate from the period before pregnancy, the preconception period (4-6). Therefore, this period offers a 'window of opportunity' to identify and anticipate timely intervention on possible risk factors associated with adverse pregnancy outcome (6).

Several studies in the Netherlands already explored ways to offer and implement preconception care (714). Most of these studies focused on women living in deprived neighborhoods, as the greatest health benefits can be achieved focusing on this group. However, none of the studies focused on women suffering from any chronic medical condition $(10,12,13)$. Possibly this is due to the assumption these women receive well-organized care as they visit their GP and disease specific specialist on a regular schedule. In practice, many of these women are referred too late to provide adequate preconception care (15). Therefore, in 2016, the Ministry of Health, Welfare and Sports ordered the Dutch Institute of Perinatal Care (CPZ) to explore how deliverance of PCC through the GP for this particular group of women could be organized. Hence, a research group with experts out of the field was consulted and developed a plan of action to implement PCC by GPs. This plan of action was discussed with involved healthcare professionals lacking a patients' point of view. Therefore, the aim of this study was to explore patients' point of view on potential facilitators and barriers to introduce PCC through GPs.

\section{Methods}

\section{Study design}

To explore patients' view on potential facilitators and barriers organizing preconception care via GPs for women suffering from chronic medical conditions, we used a qualitative approach based on a public Facebook message followed by semi-structured interviews based on for this study developed interview guide. The interview guide is provided as Additional file 1 . Women suffering from any chronic medical condition, hence a disease whereby the chance on a complete remission is not present or not to be expected (i.e. rheumatoid arthritis, diabetes mellitus, thyroid disease, inflammatory bowel disease), aged between 18-42 years, living in the Netherlands and planning to conceive were eligible for participation in the study (1). The study was approved by the Daily Board of the Medical Ethics Committee Erasmus MC (MEC 2016-386).

\section{Study setting}

The semi-structured interviews were held between January and May 2017. Two researchers (ME and AR) took turns guiding the interviews. The researchers took notes and the interviews were audio taped. The interviews were transcribed verbatim. All participants received their own transcribed interview for member checking. After consent with the content, all identifying details were anonymized to guarantee confidentiality. 
Several baseline characteristics were identified: age (in years), marital status, parity, ethnicity (selfreported), education level, type of chronic medical condition, duration of the condition based on moment of diagnosis by a GP or medical doctor, desire to become pregnant in the future. After having completed seven interviews we added a question about the type of GP practice, i.e. solo or group practice (with own GP or an alternating GP). We registered this characteristic because the first seven participants indicated that a confidential relationship between GP and patient considering discussing private issues was important.

Educational level was categorized as: low (level 0-2: early childhood; primary education; lower secondary education); intermediate (level 3-5: upper secondary; postsecondary; short cycle tertiary); or high (level 6-8: bachelor; master; doctoral).

Desire to become pregnant was defined as 'active' if the woman indicated wishing to become pregnant within two years. In all other cases, we defined the wish as 'passive'.

If a woman suffered from more than one chronic medical condition, she was classified as multi-system in type of condition.

\section{Study procedures}

We asked participants to contact the researchers in a personal message reply of the Facebook message. Then the researchers contacted women, through e-mail, and send them additional study information including a digital informed consent and an explanation of a website ZwangerWijzer.nl. This website (www.zwangerwijzer.nl), free of charge, contains an online questionnaire, which explores possible risk factors before and during pregnancy and provides standardized advice regarding to a healthy pregnancy (16). We asked women to take a look at ZwangerWijzer.nl to identify potential of ZwangerWijzer in preconception care for this specific group of women.

We discussed participants' reactions on a proposed plan of action, the organization of preconception care through GPs on request of the women involved. All participants were informed about the plan of action by the team member that contacted the participant by telephone before the interview took place. This plan of action was supplied to the information the participants received after given informed consent.

All interviews started with a brief introduction of the researcher to the participant and vice versa followed by a summary of the aim of the interview and understanding of the aim of the study. Hence, we discussed expectations, preferences and content of preconception care including ZwangerWijzer and the relevance for the patient (outcome, benefits, self-search, negative experiences, taboos).

We also explored participants' views on professionals' skills, knowledge and expectations of GPs and discussed, if applicable, participants' preparations in case of a previous pregnancy, involvement of partners and their desired organization of preconception care. Further, we asked their view on organization of preconception care in general. We asked for preferred professionals, preferred forms and 
timing of preconception care. We paid attention to socio-political issues like health care expenses and possible financial reasons as a barrier for the uptake of PCC.

\section{Statistical analysis}

A list of preliminary codes was developed through open and axial coding from the transcripts and further categorized by selective coding during analysis. Coding was performed by three researchers (ME, MS and LS) and discussed with a supervisor- researcher (AR). Selective coding to identify facilitators and barriers was based on a framework for determinants of innovation processes which exists out of four main constructs (17). The four main constructs focused on characteristics related to preconception care, the user, the organization of preconception care and the (social-political) context. After dividing the codes over the four main constructs, we divided the codes in facilitators and barriers for organizing PCC via a GP. To perform the analysis on the transcripts, NVivo10 software (QSR International) was used.

\section{Results}

A total of 45 women responded to the Facebook message. Fifteen women could not proceed in the study because of withdrawal before the interview took place $(n=4)$, not suitable for the interview (insufficient comprehension of questions and language) $(n=1)$, not available for an interview during the inclusion period $(n=4)$, after extra information no willingness to participate $(n=2)$ or cancellation by the researchers due to sufficient participants with a specific chronic medical condition $(n=4)$. In two cases, we discovered during the interview that the participant was not living in the Netherlands with a consequence that these interviews were not included in the analysis. Four interviews were not audio-taped due to technical problems and one participant concluded during the interview that she had no wish to become pregnant and therefore was excluded from the analysis. Thereby, a total of 23 interviews were included in the final analysis (Figure 1)(insert figure 1: study flow chart). All women stated that they felt privileged to be asked for input in the study.

\section{Study population}

The study population was a heterogenous group of women with chronic diseases but almost equally divided in parity, marital status and desires to become pregnant (table 1). The median age was 31 years (range 23-38) with a median duration of their medical condition of 10 years (range 2 months -20 years). The majority of the women were highly educated. After asking for the type of GP, 16 women answered. The majority ( $n=15,94 \%)$ had a GP in a group practice consisting of two or more GPs in one outpatient clinic. Of these participants, $47 \%(n=7)$ had an alternating GP within a group practice.

Table 1. Baseline characteristics of the participants $(\mathrm{N}=23)$ 


\begin{tabular}{|c|c|c|}
\hline Characteristics & $\mathbf{N}$ & $\%$ \\
\hline Age in years median (range) & $31(23-38)$ & - \\
\hline \multicolumn{3}{|l|}{ Marital status } \\
\hline Married & 12 & 52 \\
\hline Cohabiting & 9 & 39 \\
\hline Divorced & 1 & 4 \\
\hline \multicolumn{3}{|l|}{ Parity } \\
\hline Nulliparous & 12 & 52 \\
\hline \multicolumn{3}{|l|}{ Country of origin (self-report) } \\
\hline The Netherlands & 21 & 91 \\
\hline Other & 2 & 9 \\
\hline \multicolumn{3}{|l|}{ Education level } \\
\hline Low & 3 & 13 \\
\hline Intermediate & 7 & 30 \\
\hline High & 12 & 52 \\
\hline \multicolumn{3}{|l|}{ Desire to achieve pregnancy } \\
\hline Active & 13 & 57 \\
\hline \multicolumn{3}{|l|}{ Origin of medical condition } \\
\hline Gynecological & 4 & 17 \\
\hline Cardiovascular & 1 & 4 \\
\hline Endocrinological & 2 & 9 \\
\hline Gastrointestinal & 2 & 9 \\
\hline Pulmonic & 1 & 4 \\
\hline Orthopedic & 5 & 22 \\
\hline Multi-system & 5 & 22 \\
\hline Other & 3 & 13 \\
\hline Duration medical condition in years (median, range) & 10 (2 months-20 years) & \\
\hline \multicolumn{3}{|l|}{ Type of general practice* $(n=16)$} \\
\hline Solo practice & 1 & 6 \\
\hline Group practice & 15 & 94 \\
\hline
\end{tabular}


Results of coding and analyzing the interviews $(n=23)$ were described to the four constructs of a framework for implementation of innovations: characteristics of the innovation (i.e. preconception care), characteristics related to the user (i.e. patient and the GP), characteristics related to organization of preconception care and characteristics related to the (socio-political) context.

\section{First construct: Characteristics related to preconception care}

\section{a. Expectations, preferences and content of PCC, eligibility and relevance for the patient}

All participants acknowledged the benefits of PCC in general but not all of them indicated themselves as eligible for a consult or underlined the need for a consult $(n=6)$. The GP was seen for general information and first person to contact $(n=11)$. The midwife was expected to give general information about pregnancies and advise on lifestyle $(n=6)$. However, midwives played a less significant role because participants did not know a midwife offers PCC $(n=4)$. The disease specific specialist was expected to give information about complications of the medical condition and changes of medication $(n=13)$. Most participants would take the advice into consideration. In case of an advice not to become pregnant, nine participants would only follow if a pregnancy has too many risks for themselves or the fetus. In addition, four participants would still try to become pregnant, due to the fact that their desire to become pregnant was too substantial.

\section{b. Self-search for preconceptional advice or pregnancy}

Most participants $(n=20)$ knew about the patient organization websites related to their chronic condition. Twelve had viewed information about pregnancy, however mostly the website referred them to their disease specific specialist. Five participants did not find information about pregnancy on their patient organization website. However, some medical conditions were considered too rare $(n=3)$. Eight participants reached out to peers for information.

\section{c. ZwangerWijzer}

Sixteen participants were not familiar with the website ZwangerWijzer and nine were not referred to this website by a medical professional. After studying the website, it was considered to have a clear use of language $(n=7)$ and seemed complete $(n=6)$. Eight participants did not acquire new information and six times it was found not specific for their medical condition. The outcome of ZwangerWijzer would be shared with a medical professional by most participants if they were asked to $(n=11)$.

\section{Second construct: Characteristics related to the user (i.e. patient and GP)}




\section{a. Preparation previous pregnancy}

Participants who were pregnant before $(n=11)$ did not obtain information on pregnancy in combination with their chronic condition before getting pregnant and had not consulted a professional prior to their pregnancy due to the fact that the diagnosis had not been made at that time $(n=5)$ or the participant desired to have children regardless of a consult with a medical professional $(n=1)$. The other participants either consulted with their disease specific specialist $(n=3)$ or with their GP and disease specific specialist $(n=2)$.

\section{b. Partner of the patient according to the participants}

According to 15 participants, their partners would attend PCC consults. Eight partners indicated that an optimal participants' health was essential prior to achieve a pregnancy. The greater part of partners did not envision a role for the GP in PCC $(n=17)$ due to the fact that they wouldn't visit the GP for preventive health care or would rather visit a disease specific specialist. Some partners believed the GP's role was to refer $(n=5)$ and some did not have a good relationship with their GP $(n=2)$. Six partners would not mind some kind of role in PCC for their GP.

\section{c. Knowledge of GP}

The GP was assumed to have insufficient knowledge about the impact of the chronic disease on pregnancy, more specifically the related medications and pregnancy $(n=15)$. However, participants didn't mind their GP's lack of knowledge as they expected their GP to refer them to a relevant disease specific specialist. They considered the medical conditions to be too complex for the GP. The participants didn't expect the GPs to know everything about their sometimes rare conditions or medication.

\section{d. Expectation of $G P$}

The GP was believed to be an advisor on lifestyle and nutrition in general $(n=5)$. The GP must acknowledge to what extent he or she thinks the information should be provided to the patient, as some indicated that they would rather want to look by themselves. The GP was expected to have a more proactive attitude, so offer more support when needed and check up on you. The patients mainly wanted their GP to have a coordinating role.

\section{e. Mental health support by GP}

The GP was considered to be a trustworthy professional, whom you would visit most often and most easily, and preferably practices in the neighborhood of the patient $(n=14)$. Despite these advantages, some patients would rather visit a psychologist for mental health support $(n=3)$. Two patients indicated that they would rather not discuss their mental health with their GP.

\section{Third construct: Characteristics related to the organization of preconception care}

\section{a. Actively asking by GP for PCC}


When GPs actively asked patients about their desire to have children, it was appreciated. Similarly, when the GP was consulted to check up on their chronic disease $(n=9)$ or about other complaints $(n=10)$, actively asking was appreciated. However, three participants would find it inappropriate to be actively asked, if the consult was about other complaints. They indicated it would be unexpected and it should be introduced first with a pamphlet as it could be that they weren't interested in gaining information on pregnancy. Four participants suggested that prior to that question they would like to have an explanation about why the GP wanted to have information about planning a pregnancy and suggested that the GP should sense the timing of that question.

\section{b. Preferred professional and form}

The preferred professional for general information on PCC was the GP $(n=9)$, because the GP is most aware of the medical history and social situation and following this referral is still possible to a disease specific specialist who could confirm the safety of the chosen process to become pregnant. Eleven participants would like to have a PCC consultation with an obstetrician, preferably jointly with their own disease specific specialist. In two cases the disease specific specialist, not the obstetrician, was preferred for specialized individual preconception care due to having the most knowledge on the medical condition. Two participants preferred a specialized nurse because she would have specific knowledge on the medical condition and would have more time and patience than a doctor. The most preferred form of PCC consult was a face-to-face consultation, because participants $(n=12)$ indicated that this was a private matter.

\section{c. Referral after PCC consult}

If the GP indicated the need for a referral to a disease specific specialist, most participants would make an appointment $(n=12)$ with the main reason to become well-informed. Two participants would only make a referral appointment when referred to a disease specific specialist, not to other professionals like a midwife $(n=2)$. They thought midwives were only qualified for providing pregnancy care and didn't know that midwives offered PCC.

\section{d. Ideal situation}

Seven participants described their ideal situation of receiving a timely referral from their GP to a disease specific specialist for PCC. Others described their ideal situation as discussing pregnancy and their condition with a GP to get better informed $(n=2)$; with their disease specific specialist $(n=3)$ or in a joint contact with an obstetrician and disease specific specialist $(n=11)$.

The timing of PCC was ideally before they ceased contraception $(n=8)$; when their chronic condition was more stable $(n=3)$; when they didn't succeed in conceiving naturally $(n=2)$; after ceasing medication, but before ceasing contraception $(n=1)$.

\section{Fourth construct: Characteristics related to the (socio-political) context}

\section{a. Taboo}


Six participants decided not to tell family and friends about their desire to become pregnant, simply because of their own choice. None of the participants felt pressure to have a conversation with a medical professional about their pregnancy consideration, mostly because their community would understand the importance of a well-informed decision. Furthermore, 17 women didn't experience feelings of taboo when discussing their desire to become pregnant with someone other than their partner.

\section{b. Fear of negative reactions}

Eleven participants experienced negative reactions when discussing their considerations of achieving a pregnancy with family or friends. Four women were questioned by their community whether she would be able to raise a child due to the impediment their medical condition has on daily activities and financial concerns $(n=4)$. Other concerns of the participants were about the effect of the pregnancy on the medical condition, the effect of the condition on the fetus and the genetic transferability which led to family and friends to reject and discuss the wish to become pregnant.

\section{c. Health care expenses for PCC}

Fifteen participants who did pay for their PCC did not consider it a barrier to accessing PCC. Five indicated that their deductible excess would be used entirely every year. These participants also indicated that if they didn't have the financial means or didn't spend all their deductible excess because of their chronic condition, paying for PCC would become a barrier to make a GP appointment and it would make the GP less approachable. Some participants $(n=8)$ would be hindered to visit their GP when having to pay for PCC.

Based on the four constructs, an overview of facilitators and barriers could be derived (table 2). Barriers were mainly focused on unfamiliarity with roles of GPs and midwives or untraceability of information and on fear for negative reactions. Facilitators focused on benefits achieved by PCC, pro-active support of GPs and partners and the form of a PCC consultation.

Table 2. Overview of facilitators and barriers for organizing preconception care via general practitioners for women suffering from chronic diseases 


\begin{tabular}{|c|c|c|c|c|}
\hline & $\begin{array}{l}\text { Preconception } \\
\text { care }\end{array}$ & Users & Organization & $\begin{array}{l}\text { Socio- } \\
\text { political } \\
\text { context }\end{array}$ \\
\hline \multirow[t]{4}{*}{ Facilitators } & $\begin{array}{l}\text { Benefits that can } \\
\text { be achieved by } \\
\text { PCC }\end{array}$ & $\begin{array}{l}\text { Pro-active support of } \\
\text { partners }\end{array}$ & $\begin{array}{l}\text { PCC by disease specific } \\
\text { specialist and obstetrician in } \\
\text { a one stop-shop principle } \\
\text { (face-to-face) }\end{array}$ & $\begin{array}{l}\text { PCC free } \\
\text { of } \\
\text { charge }\end{array}$ \\
\hline & $\begin{array}{l}\text { Sharing } \\
\text { outcomes of } \\
\text { ZwangerWijzer }\end{array}$ & $\begin{array}{l}\text { GPs role in } \\
\text { supporting mental } \\
\text { health issues and } \\
\text { PCC }\end{array}$ & & \\
\hline & & $\begin{array}{l}\text { GPs practices in own } \\
\text { neighborhood with } \\
\text { enables quick entry to } \\
\text { GP care }\end{array}$ & Pro-active support of GPs & \\
\hline & & $\begin{array}{l}\text { Trust in and good } \\
\text { relationship with GPs }\end{array}$ & Coordinating role of GPs & \\
\hline \multirow[t]{2}{*}{ Barriers } & $\begin{array}{l}\text { Unknown role of } \\
\text { midwives } \\
\text { regarding PCC }\end{array}$ & $\begin{array}{l}\text { Perceived lack of } \\
\text { knowledge of the GPs } \\
\text { by patients }\end{array}$ & $\begin{array}{l}\text { No role for GPs according to } \\
\text { partners }\end{array}$ & $\begin{array}{l}\text { Fear of } \\
\text { negative } \\
\text { reactions }\end{array}$ \\
\hline & $\begin{array}{l}\text { Finding of } \\
\text { information on } \\
\text { patient } \\
\text { organization } \\
\text { websites }\end{array}$ & $\begin{array}{l}\text { Not indicating } \\
\text { themselves as } \\
\text { eligible for or need of } \\
\text { PCC }\end{array}$ & & \\
\hline
\end{tabular}

\section{Discussion}

\section{Main findings}

In this study apparent facilitators and barriers towards the role of the GP in offering PCC to women suffering from chronic medical conditions have emerged. Main facilitators are trust, a good relationship with a GP, a supporting partner and actively asking by the GP within a clear framework. Main barriers are a perceived lack of knowledge of the GP on the chronic disease and effect on pregnancy, the preference to have PCC in a joint consultation of an obstetrician and disease specific specialist and the organization of care within GP group practices.

\section{Strengths and limitations}

For as far as we know, our study is the first Dutch study about PCC for women suffering from a chronic medical condition, focused on the patient's point of view and thereby highly relevant. Through our public 
Facebook message, we reached a broad spectrum of women with chronic medical conditions in different stages and in different phases of planning a pregnancy. Therefore, we were able to consider PCC from different perspectives. However, when interpreting our results, certain limitations should be taken into account such as the relatively small sample size and the influence of potential bias. Although the sample size was small, we did obtain a mixture of different medical conditions and reached data satisfaction. After 23 interviews, there were no new insights. Therefore, we believe that the sample of participants was sufficient and a good reflection of the general opinion of women suffering from a chronic condition.

Bias may also be a result from our sample of highly educated and motivated participants who were interested in PCC. However, this is often the case with this sort of studies, generally only motivated people are reached to participate (18).

Finally, we started registration of the type of GP practice after seven interviews, because the first seven participants indicated that the relationship between GP and patient considering discussing private issues was important. Therefore, there is some missing data. This states the strength of a qualitative study. Because of new insights it is possible to optimize the interviews during the study.

\section{Interpretation}

In a previous study in Rotterdam $60-80 \%(n=457)$ of the participants indicated they preferred to receive PCC from their GP (19). These results correspond with our study, although in our study the GP was mainly seen as a coordinator and not as the provider of PCC. A British study $(n=705)$ regarding actively asking for PCC by the GP found that $90 \%$ of the women appreciated the topic when the consult was about contraception (20). When the purpose of the consult was a cervical smear, $50 \%$ of the women did not mind the GP's question about planning to become pregnant. However, only $8 \%$ found it appropriate to discuss PCC when the consult was about the flu (20). In our study we only differentiated between a consult about the chronic condition and about other complaints. The participants appreciated the GP's effort and most of them didn't think or experienced it as interference.

Adverse perinatal outcomes for both mother and child are more common when mothers suffer from a chronic disease. The impact of risk factors like chronic diseases on perinatal outcomes can be reduced or in some cases eliminated, if timely PCC is offered to these women and steps can be taken to reduce the impact (3). Hence, this opportunity calls for a systematic approach like van Voorst et al., recommended in 2016 (21). Same as, recent studies from Atrash and Jack which can be used to improve PCC consultations as they describe several evidence based clinical interventions and guidelines for implementation of PCC (7-9). Tailoring PCC towards womens' needs and offering PCC during routine contacts are main points of attention. In this, the GP can play an important role by giving information and coordinating the care. Moreover, if the relationship with the GP is strengthened and the GP shows a proactive attitude, and offers mental health support, more patients are willing to discuss PCC with the GP. A supportive role could be played by the patient's partner as they can influence patient's considerations about the GP's role in PCC. 


\section{Conclusion}

This study applied specifically to PCC for women suffering from a chronic medical condition through GP care in the Netherlands, from a patient's point of view. All participants were enthusiastic that they were asked in advance to provide input on the plan of action as suggested by the project team before an implementation study was rolled out.

The study revealed clear facilitators and barriers which must be taken into account before organizing PCC via GPs for this specific group. The results offered opportunities to tailor a follow-on implementation study to the needs and wishes in the organization of PCC for women with chronic diseases and a wish to conceive. Furthermore, if PCC should be implemented for other target groups, it is important to tailor proposed plans of action to their specific demands. This study could be used as an example on how to evaluate these needs.

Additionally, to improve the uptake of PCC by education, more information about pregnancy must be made available on chronic disease organization websites. This is an opportunity for disease specific specialists and consumer groups to cooperate to provide enhanced information.

\section{Abbreviations}

CPZ: the Dutch Institute of Perinatal Care; GP: general practitioner; ICPC: International Classification of Primary Care; PCC: preconception care.

\section{Declarations}

\section{Ethics approval and consent to participate}

The study was approved by the Daily Board of the Medical Ethics Committee Erasmus MC (MEC 2016386).

\section{Consent to publish}

All participants fulfilled a digital informed consent for publication.

\section{Availability of data and material}

The datasets used and/or analyses of the current study are available from the corresponding author on reasonable request.

\section{Competing interests}

None of the authors have any financial or non-financial competing interests.

Funding 
Not applicable

\section{Authors' contribution}

AR outlined the study in collaboration with a project group. ME and AR performed the recruitment and the interviews. ME, MS and LS transcribed and coded the interviews. The coding was discussed with AR. ME, MS and LS wrote a first draft of the manuscript. LA, AM and AR finished the manuscript.

\section{Acknowledgements}

We would like to thank all participants of the interviews and we are grateful for their time, effort and openness. We also thank Prof. dr. H.P Verloove-van Lorick (neonatologist), Drs. T. Slagter (GP) and Drs. A.L. Drost (implementation expert) for their contributions in the project group.

\section{Authors' information}

LA is a resident and working at the department of Obstetrics and Gynecology, Erasmus MC, University Medical Center Rotterdam, , Rotterdam, the Netherlands.

MS is a resident and working at the obstetric department of the ISALA, Zwolle, the Netherlands.

ME is now a resident and working at the obstetric department of the Curaçao Medical Center, Curaçao but at the time of the research she was working as a medical student at the department of Obstetrics and Gynecology, Erasmus MC, University Medical Center Rotterdam,, Rotterdam, the Netherlands

LS is a medical student at the Amsterdam UMC, Amsterdam, the Netherlands

AM is a consultant obstetrician working at the department of Obstetrics and Gynecology, Erasmus MC, University Medical Center Rotterdam, Rotterdam, the Netherlands

AR is a midwife, lector and teacher. She worked during the research as senior-researcher at the department of Obstetrics and Gynecology, Erasmus MC, University Medical Center Rotterdam,.

\section{References}

1. Public health and care. Available from: https://www.volksgezondheidenzorg.info/onderwerp/chronische-ziekten-en-multimorbiditeit/cijferscontext/huidige-situatie\#definitie--node-wat-een-chronische-aandoening on October 20th, 2019

2. Nederlands Huisartsen Genootschap: NHG HIS table 24 ICPC version 4 2009. Available from: https://www.nhg.org/sites/default/files/content/nhg_org/uploads/icpc-versie-4inkijkexemplaar_0.pdf.

3. Dunlop AL, Jack BW, Bottalico JN, Lu MC, James A, Shellhaas CS, et al. The clinical content of preconception care: women with chronic medical conditions. Am J Obstet Gynecol. 2008;199(6 
Suppl 2):S310-27.

4. Atrash HK, Johnson K, Adams M, Cordero JF, Howse J. Preconception care for improving perinatal outcomes: the time to act. Matern Child Health J. 2006;10(5 Suppl):S3-11.

5. Bianco-Miotto T, Craig JM, Gasser YP, van Dijk SJ, Ozanne SE. Epigenetics and DOHaD: from basics to birth and beyond. J Dev Orig Health Dis. 2017;8(5):513-9.

6. Steegers-Theunissen RP, Steegers EA. Embryonic health: new insights, mHealth and personalised patient care. Reprod Fertil Dev. 2015;27(4):712-5.

7. Atrash H JB. Preconception care to improve pregnancy outcomes: clinical practice guidelines. J hum Growth Dev. 2020;30(3):353-62.

8. Hood JR, Parker C, Atrash HK. Recommendations to improve preconception health and health care: strategies for implementation. J Womens Health. 2007; 16(4):454-7

9. Atrash H JK. Preconception care for improving perinatal outcomes: time to act. Matern Child Health J. 2006;10(5 Suppl):S3-11.

10. Denktas S, Bonsel GJ, Van der Weg EJ, Voorham AJ, Torij HW, De Graaf JP, et al. An urban perinatal health programme of strategies to improve perinatal health. Matern Child Health J. 2012;16(8):15538.

11. Poels M, van Stel HF, Franx A, Koster MPH. The effect of a local promotional campaign on preconceptional lifestyle changes and the use of preconception care. Eur J Contracept Reprod Health Care. 2018;23(1):38-44.

12. Sijpkens MK, van Voorst SF, de Jong-Potjer LC, Denktas S, Verhoeff AP, Bertens LCM, et al. The effect of a preconception care outreach strategy: the Healthy Pregnancy 4 All study. BMC Health Serv Res. 2019;19(1):60.

13. Temel S, Birnie E, Sonneveld HM, Voorham AJ, Bonsel GJ, Steegers EA, et al. Determinants of the intention of preconception care use: lessons from a multi-ethnic urban population in the Netherlands. Int J Public Health. 2013;58(2):295-304.

14. van der Zee B, de Beaufort I, Temel S, de Wert G, Denktas S, Steegers E. Preconception care: an essential preventive strategy to improve children's and women's health. J Public Health Policy. 2011;32(3):367-79.

15. M'Hamdi H I, van Voorst SF, Pinxten W, Hilhorst MT, Steegers EA. Barriers in the Uptake and Delivery of Preconception Care: Exploring the Views of Care Providers. Matern Child Health J. 2017;21(1):218.

16. Landkroon AP, de Weerd S, van Vliet-Lachotzki E, Steegers EA. Validation of an internet questionnaire for risk assessment in preconception care. Public Health Genomics. 2010;13(2):89-94.

17. Fleuren MA, Paulussen TG, Van Dommelen P, Van Buuren S. Towards a measurement instrument for determinants of innovations. Int J Qual Health Care. 2014;26(5):501-10.

18. Goodman A, Gatward R. Who are we missing? Area deprivation and survey participation. Eur J Epidemiol. 2008;23(6):379-87. 
19. Denktaş S SHM, Birnie E, van der Weg E.J, Voorham A.J.J, Peters I.A, et al. Rapportage eerste jaar pilotstudie preconceptiezorg in deelgemeente Noord 2010. Available from: http://hdl.handle.net/1765/39245.

20. Wallace M, Hurwitz B.Preconception care: who needs it, who wants it, and how should it be provided? Br J Gen Pract. 1998;48(427):963-6.

21. van Voorst S, Plasschaert S, de Jong-Potjer L, Steegers E, Denktas S. Current practice of preconception care by primary caregivers in the Netherlands. Eur J Contracept Reprod Health Care. 2016;21(3):251-8.

\section{Figures}

Total number of women responding the public Facebook message $(n=45)$

Women excluded $(n=15)$

- Withdrawal of their application $(n=4)$

- Not suitable for the interview $(n=1)$

- Not available during the inclusion period $(n=4)$

- After extra information no willingness to participate $(n=2)$

- Cancellation by researchers due to sufficient participants with a specific chronic medical condition $(n=4)$

Conducted interviews $(n=30)$

Excluded interviews ( $n=7$ )

- Not residing in the Netherlands $(n=2)$

- Not audiotaped due to technical problems $(n=4)$

- No desire to become pregnant $(n=1)$

Total interviews included for analysis $(n=23)$

Figure 1

study flow chart

\section{Supplementary Files}

This is a list of supplementary files associated with this preprint. Click to download.

- Additionalfiles1finalrevised.docx

- 20201103Qorecchecklist.docx 